\title{
Examining consent within the patient-doctor relationship
}

Marwan A Habiba University of Leicester, Faculty of Medicine and Biological Sciences, Leicester

\begin{abstract}
The notion of consent which rose to the forefront in biomedical ethics as an attempt to safeguard patients' autonomy, is relatively new. The notion itself requires qualification, for it precludes neither duress nor ignorance. More seriously, I argue here that consent is redundant except in situations where paternalism prevails. Paradoxically, these are the very situations where it may be difficult to uphold or to verify voluntary consent. I suggest that a request-based relationship has the potential to overcome these difficulties. It enhances patients' participation in decision making, requires that the patients remain in command and avoids their subordination. Request is also more conducive to treatments that are representative of patients' own values and perceptions. In practice, what one wants and what one agrees to, often concur. But these are not conceptually identical issues, and they carry important differences of emphasis.

(Fournal of Medical Ethics 2000;26:183-187)
\end{abstract}

Keywords: Consent; request; paternalism

\section{Introduction}

Consent has not featured as a central part of the patient-doctor relationship until very recent times; there is no reference to the concept in Egyptian, Greek, or Roman medicine. It is plausible that this lack of emphasis came about because, ordinarily, it was patients who sought the help of the physicians who, in turn, acquired a position of trust as they pledged beneficence and nonmaleficence. One can envisage how this became a sufficient basis for the therapeutic relationship without recourse to the notion of consent. It is possible that the central role of consent evolved as a response to recent instances where certain groups or minorities were subjected to, or at the threat of, reprehensible degrees of compulsion. It is also possible that it acquired momentum in parallel with ideas of individual liberty or freedom of choice. ${ }^{1}$ Polani links the evolution of consent in medicine to the general change of attitude towards rights and duties, to a new spirit of scrutinising the rules governing human interactions, and to the development of sophisticated treatments. He also links it to a breakdown of the caring one-to-one relationship, which resulted from the involvement of larger clinical teams in the management of complex conditions, and to the heightened expectations on the part of the patient, coupled with increased uncertainty about the efficacy of the interventions. Within this context, consent is seen as a new code of practice for the medical profession, motivated by societal changes. ${ }^{2}$ Only a few references to consent exist in earlier literature, and more exceptionally in codes of practice. ${ }^{23}$ The term "informed consent" did not appear until a decade after the Nuremberg Code. ${ }^{4}$

In this article, I examine consent in relation to liberty and, within that context, the contribution of consent in its common usage, to the practice of medicine and the therapeutic patient-doctor relationship. Therefore this discussion will not be concerned with the researcher-subject relationship, which ought to be founded on unequivocal adherence to consent as laid down in the first of the ten standards of the Nuremberg Code.

\section{Problems with consent}

Consent is defined in a number of ways. To Polani it means compliance or approval, especially of what is done or proposed by another. It signifies capable, deliberate agreement to, or concurrence in, some act or purpose, and implies physical and mental power. ${ }^{2}$ The New Oxford Dictionary's definition of the word is "permission for something to happen or agreement to do something". 5 Two important qualifications can be mentioned, first: the word consent as such does not require, although it may imply, some knowledge or understanding. For example, in consenting to undergo an operation for the removal of breast cancer, which in fact involves the removal of the breast, the patient may have the belief, which is not made clear, that it is the tumour but not the whole breast that will be removed. To avert this difficulty the doctrine was developed of "informed consent". This is used to mean "permission granted in the knowledge of the possible consequences". ${ }^{5}$ Just what constitutes an informed consent has been a focus of debate in medical and legal circles, but 
suffice to say here that consent can be regarded as ethically sound without it being fully informed. An example would be the patient who contends that s/he would rather not know.

Whether voluntariness is implied by the use of the term is also open to question. Contrary to the above-mentioned definitions, The Oxford English Dictionary, compact edition, defines consent as a "voluntary agreement to, or acquiescence in, what another proposes or desires, compliance, concurrence, permission". ${ }^{6}$ The common emphasis on non-coercion in relation to consent implies that the notion as such does not signify voluntary agreement, nor does it imply the absence of persuasive pressures. In the political realm, consent is modelled on the private promise, and is taken to be morally binding, usually but not always, because of its being a voluntary act. Examples of involuntary but "morally binding" consent are the act of surrender in war, or exacting oaths of allegiances to conquerors or usurpers. ${ }^{7}$ Two points are clear here; firstly involuntary acceptance can, in certain circumstances at least, be described as consent; secondly, consent as in the examples above, can be the basis for levying obligations on the consenting party. In his discussion of the evolution of consent, Polani points out that it became a political reality in England when the barons, the knights of the shire and the burgesses in mediaeval parliaments asserted their corporate right to grant or withhold subsidies to the King. ${ }^{2}$ In this context, it could be argued that although the notion may appear to safeguard liberty, in fact once consent is given it entails binding obligations. Obligations, in as far as they entail surrendering some rights or liberties conflict with, or are a limit to, individual freedom. Thus it could be argued that liberty cannot be ensured unless consent is either withheld or (once given) the freedom to withdraw it is maintained, and that, therefore, it is the absence of consent, or the ability to withdraw it, and not its presence that safeguards liberty. This argument it not weakened through an appeal to any benefits one may exchange for forgone liberty because consent as such neither necessitates nor implies that any such exchange has taken place. On the other hand, although the possibility not to give consent safeguards liberty, it only does so until consent is given.

\section{Uses of the notion of informed consent in medical ethics}

Despite the difficulties referred to above, the notion of consent in biomedical ethics usually means a voluntary uncoerced decision, made by a competent autonomous person, to accept rather than reject some proposed course of action. Gillon, ${ }^{9}$ argued that consent in medicine should be based on adequate information and deliberation, and that it is therefore, by definition, an "informed consent".

As mentioned above, discussions about informed consent often centre on how much information patients need, or, as doctors are perceived by the profession and by the law as the main source of information, on how much information doctors should give to patients. Indeed, indications dating back to Hippocrates point towards the fact that treatments may not have been discussed with patients, especially if discussion was judged to be against their interests. This practice persists in modern times, and is sometimes endorsed by professional bodies under the protestation that this may protect patients or the doctorpatient relationship. ${ }^{10}$

Consent has now evolved into an a priori essential component of the doctor-patient relationship, and has also been defended through an appeal to some other utilities. For example, it is said to provide a defence for doctors against legal liabilities, to encourage patient cooperation, to provide a response to society's emphasis on individuals' dignity and rights, and to represent an attempt to promote self determination. ${ }^{10}$

\section{The doctor-patient relationship}

The role of consent in the therapeutic relationship is best explored in relation to the different proposed models for the patient-doctor interaction. It is not my intention here to delve into the merits or the utility of these models, or to explore whether the patient-doctor interaction could in fact be moulded according to any predetermined model. Nevertheless, I shall use these as a framework within which to demonstrate the factors that influence the relationship and the role of consent. Models of the patient-doctor relationship differ only in emphasis, not in the type of influences that are brought into play. This makes it possible to extrapolate from the following discussion, which because of the limitation of space will be limited to two models, to other models.

One view of the patient-doctor relationship is provided by the psychoanalytical model of Szasz and Hollender, ${ }^{11}$ who saw the concept of the relationship as an abstraction appropriate for the description and handling of observational facts. They argued that the forms the relationship may take are ubiquitous in human interactions, but that what makes the relationship unique is the particular technical or social setting in which it takes place. According to this view, the interaction may take the activity-passivity form, which bears 
similarity to the parent-infant relationship. Here the physician "does something to the patient" who in turn adopts a "recipient unable to respond or inert role"; one example is the case of the comatose patient. Alternatively, it may take the form of guidance-cooperation, where the doctor "tells the patient what to do" whilst the patient cooperates or obeys. The third form is the mutual participation model where the physician "helps the patient to help himself" whilst the patient "participates in a sort of partnership that uses the help of the expert". Another model for the relationship is put forward by Emanuel and Emanuel, ${ }^{12}$ who begin their exploration by posing the question: "what should be the ideal physicianpatient relationship?" They see the relationship as based on conflict between patients' autonomy and health, or between values held by patients and those held by doctors. They described four forms for this relationship: the paternalistic, the informative, the interpretive and the deliberative. Here the paternalistic form appears to fall somewhere between the activity-passivity form and the guidance-cooperation form referred to in the psychoanalytical model. ${ }^{12}$ It can, perhaps, be referred to as a guidance-submission form where the "physician acts as the patient's guardian, articulating and implementing what is best for the patient" who in turn "assents either at the time or later" to the physician's decisions. In the informative form, the role of physicians is restricted to the provision of factual information whilst patients make up their minds and formulate their wishes. Emanuel and Emanuel view this form as theoretical, in so far as the physician appears to be more akin to a talking textbook or a skilled robot whose role goes no further. The role of the physician in the interpretive form is that of "elucidating and interpreting patients' values as well as providing information and implementing the patients' choices". In the deliberative form this role becomes that of "articulating and persuading the patients of the most admirable values, as well as informing the patients and implementing the patients' selected interventions". Thus both the interpretive and the deliberative forms share with the mutual participation form the emphasis on some type of partnership. The deliberative form also shares with the paternalistic form the emphasis on enforcing patients' welfare as interpreted by the physician. The similarities between these two models and other conceptions of the patientdoctor relationship, stem from the fact that they all describe different points in the balance between the degree of activity-passivity that each party brings into play, as well as taking into account the degree to which the physician allows his value judgment to influence the decisions made. As mentioned above, it is not my objective to address the relative merits of each, but rather to compare the importance each places on consent.

In relation to the psychoanalytical model consent is clearly irrelevant to the activitypassivity form, where patients have no say in what will be performed on them. Consent also appears superfluous in a mutual participation form, for as is the case in other day-to-day activities, it is not clear why one should be required to consent to what one has requested. The idea of giving consent to what one requests is redundant. This is particularly the case in those forms of the relationship that imply that the patient retains the leading position, making his own choices. In the guidance-cooperation form it is assumed that patients are ready and willing to cooperate because of their suffering. Here one of two possibilities may exist; firstly that patients, whilst exercising their free autonomy, place physicians in a temporary position of power, whilst retaining overall control, which includes the freedom to discharge physicians. Within this scenario the concept of consent becomes implicit in the act of appointing the physician, and serves no purpose beyond protecting doctors through proving that they acted within the remit of their appointment, ie a sort of authorisation. The second possibility is that the relationship is, or becomes, in some way binding on patients (as may be implied in the general use of the term, "binding"). But to establish a patient-doctor contact or to enforce compliance within this context, requires an element of coercion that lies outside of the patient's own motivations. I would argue that it is only within this last scenario that consent may have a conceptually valid role. But, paradoxically, these are the very situations where consent could not be verified to be voluntary and consequently ethically acceptable. Clearly, the presence of coercion also diminishes patients' ability not to consent, and the use of coercion precludes voluntary consent. A similar relation could be drawn between consent and the different forms within the model described by Emanuel and Emanuel. ${ }^{12}$ Consent becomes redundant unless the physician is seen as somebody who "does something to the patient", either with inadequate or no explanation, as in the so-called paternalistic model, or after endeavouring to "persuade the patient of the most admirable values" as in the deliberative model. The idea of consent thus necessitates a dominant-subordinate type of relationship, or the type of relationship that conflicts with the ideals of liberty and autonomy which consent is meant to create. The concept of consent does nothing to rectify the subordination 
of the consenting party; instead, through lending credence to morally dubious interactions, it acts to exacerbate dependency and subordination. Consent within the doctor-patient relationship is not incompatible with doctors maintaining the commanding position of indicating the choices with which they themselves feel more comfortable. It is true that it restrains interference without prior authorisation, but this falls short of a relation where patients remain in command, and where the demand for information, explanation, or support will stem from their own perspective and perception. Thus it appears that consent is conceptually irrelevant in a relationship based on respect for liberty and autonomy, for it is not the person who consents who is free but the one who withholds or withdraws consent.

The patient-doctor relationship is normally initiated by autonomous patients who seek advice from doctors ie, by a request; it can also be seen that patients maintain their freedom to terminate the relationship through withdrawal of that request. Consent within this scenario can only be a reflection of role reversal with doctors gaining command, and, I argue, it adds nothing to patients' protection, which cannot be addressed within the notion of request. The idea of request, although recognised in medical ethics, ${ }^{10}$ remains inadequately developed. Clearly it could be criticised as being inapplicable to those who are unable to formulate a request, such as the comatose or the under-age. Here, acting in the best interest, based on the assumption that patients would have requested the specific interference had they been able to, would restrict the limits of interference, and would also provide a helpful, although not a decisive, framework. However, if the criticism were raised in relation to mentally competent adults who are unable or unwilling to request medical interference, because of their particular social, educational, religious, or any other values, I argue that respect for these individuals and for their liberty and autonomy must prohibit any attempt to influence their preferences in order to obtain or extract their consent. A request-based doctor-patient interaction, is necessarily an expression of patients' own volition, and a reflection of their knowledge and values. Request does not connote role reversal or a provider-dominated relationship, it enables patients through placing them not only at the centre of care, as in a consent-based relationship, but also at the centre of responsibility for decision making. This, of course, will raise questions regarding the qualities that are required for an informed request, which must remain a question for the individual patient to address. Some will require more detailed infor- mation, and this will be reflected in the eagerness with which they pursue relevant knowledge. Doctors will necessarily be an important, but not the only, source of such knowledge. It is important here to stress that issues of health are primarily value judgments, and that a system based on request will place more emphasis on each individual's own outlook and on his/her perception of the way in which his/her health needs ought to be addressed.

\section{Consent and paternalism}

It is interesting that writings in medical ethics have often presented consent as the antidote to paternalism. But paternalism itself is the power and authority one person or institution exercises over another in order to confer benefits on, or prevent harm to, that person, regardless of the person's informed consent. ${ }^{13}$ Similarly, Beauchamp uses the term to "refer to practices that restrict the liberty of individuals, without their consent, where the justification for such actions is either the prevention of some harm they will do to themselves or the production of some benefit for them that they would not otherwise secure". ${ }^{14}$ Paternalism is distinct from beneficence and entails the exercise of power or authority. It could indeed be argued that as the doctors' power in the context of the doctor-patient relationship ought to be conferred only by the patients themselves, and that whilst patients retain the right to withdraw that power, such a paternalistic relation should not exist. It is interesting to note that despite common usage, the activity-passivity form of Szasz and Hollender, ${ }^{11}$ which operates if the patient is unable to give consent, does not fulfil the above quoted requirements of paternalism. Moreover, a paternalistic form like that described by Emanuel and Emanuel, ${ }^{12}$ cannot exist unless forces outside individuals', and within doctors', reach compel patients to undergo what they refuse. These forces or powers cannot be those of an unpleasant illness or suffering as they are outside the control of doctors who practise "paternalism", nor is it part of the doctor-patient interaction that doctors manipulate suffering to enforce compliance. Furthermore, if illness itself were of sufficient power to establish, or authorise, paternalism, one would have to accept a description of the term that had the potential to include all doctor-patient relationships. This is not the case. That severity of illness is not a sufficient basis for paternalism can also be demonstrated by the fact that all severe illnesses can be managed within a non-paternalistic relationship. It thus becomes clear that the centre of power in paternalism resides outside the illness, be it in a 
moral, legal, or other authority. The concept of consent in the context of such authority will be paradoxical, for it is only if such outside influences are removed that patients can give truly voluntary consent. Thus it is autonomy and not consent that guarantees a non-paternalistic relationship. The form of "acceptable" paternalism, advocated for example when a doctor withholds information for the patient's own good, is difficult to defend for it cannot lead to a valid request, any more than it can lead to a valid consent.

\section{In conclusion}

Consent has become a dominant concept in medical ethics, and its strength has been enhanced by its incorporation in the declarations of Helsinki, in the World Medical Association's declaration on the rights of the patient (Declaration of Lisbon), and in codes dealing with research. The upsurge of anti-paternalism has indicated the enforcement of the notion that consent should be "informed". In this article I have focused on the traditional therapeutic doctorpatient relationship, initiated by patients themselves for the relief of what they perceive as their health problems. Typically the consultation would culminate in a prescription, counselling, an operation, or further investigations. I have pointed out some of the difficulties inherent in a shift from a request- to a consent-based relationship, and in doing so, argued that such a shift requires justification and should take into consideration respect for patients' autonomy. I have also argued that consent cannot be required without envisaging a paternalistic relationship, and this remains true irrespective of the amount of information or the number of different options that the patient may be offered.

The idea of giving consent to what one requested is to say the least, redundant, and at most implies subordination, which is paradoxical given that consent is meant to be an enabling notion. The model envisaged here is that of wellinformed patients who reach their decisions (possibly after consultation with the relevant health care professional), and who elect to enlist the help of professionals to achieve their goals. It could be argued that what should be sought is the doctor's consent to carry out the procedure, and it is within this context that the doctor ought to exercise his/ her duties of beneficence and non-maleficence.

The concept of request has the potential to overcome the difficulties with consent, but will need to be developed further and to be explored in different clinical situations. It does not relieve doctors of the duty of full explanation and disclosure, on the contrary, these become necessary requisites if patients are to be able to understand their options and reach their conclusions. With "request" patients remain in control and this encourages responsibility for their own health, and the doctors' duty changes from obtaining an informed consent, to fulfilling an informed request.

\section{Acknowledgement}

I thank Dr Martyn Evans and Mr Hugh Upton, Centre of Philosophy and Health Care, University of Wales Swansea, for their useful suggestions and comments on the manuscript.

Marwan Habiba, MSc, PhD, MRCOG, is a Senior Lecturer in the Department of Obstetrics and Gynaecology, University of Leicester School of Medicine, Leicester. Correspondence to: M A Habiba, Senior Lecturer, Department of Obstetrics and Gynaecology, University of Leicester School of Medicine, Clinical Sciences Building, Leicester Royal Infirmary, Leicester LE2 $7 L X$

\section{References}

1 Balint J, Shelton W. Regaining the initiative, forging a new model of the patient-physician relationship. Fournal of the American Medical Association 1996;275:887-91.

2 Polani PE. The development of the concepts and practice of patient consent. In: Dunstan GR, Seller MJ, eds. Consent in medicine. London: King's Fund Publishing Office, 1983:57-84.

$3 \mathrm{Katz}$ J. The Nuremberg Code and the Nuremberg trial. Fournal of the American Medical Association. 1996;276:1662-6.

4 Beauchamp TL, Childress JF. Principles of biomedical ethics. New York, Oxford: Oxford University Press, 1989.

5 The new Oxford dictionary of English. Oxford: Oxford University The new Oxford 1998 .

6 The Oxford English Dictionary, compact edition. Oxford: Oxford University Press, 1991

7 Walz M. Consent. In: Honderich T, ed. The Oxford companion to philosophy. Oxford, New York: Oxford University Press, 1995:153-4.

8 Gray T. Freedom. In: Jones P, Weale A, series eds. Issues in political theory. London: Macmillan, 1991: 3-16.

9 Gillon R. Philosophical medical ethics. Chichester: John Wiley \& Sons, 1985:113-8.

10 British Medical Association's Ethics, Science and Information Division. Medical ethics today: its practice and philosophy. London: BMJ Publishing Group, 1993.

11 Szasz TS, Hollender MH. The basic models of the doctorpatient relationship. Archives of Internal Medicine 1956;97:58592 .

12 Emanuel EJ, Emanuel LL. Four models of the physicianpatient relationship. fournal of the American Medical patient relationship. fournal

13 Bedau HA. Paternalism. In: Honderich T, editor. The Oxford companion to philosophy. Oxford, New York: Oxford University Press, 1995:647.

14 Beauchamp TL. Paternalism. In: Reich WT, ed. Encyclopedia of bioethics. New York: Free Press; London: Collier Macmillan, 1978:1194-1200. 